PONTIFÍCIA UNIVERSIDADE CATÓLICA DO RIO DE JANEIRO

ANÁLISE DO COMPORTAMENTO DA GERAÇÃO Y DO RIO DE JANEIRO DE NITERÓI NAS DECISÕES DE COMPRA EM SITES DE MODA

Isabella Barreira de Sá Pacheco

Trabalho de Conclusão de Curso

Centro de CIÊnCIAS SOCIAIS - CCS

Departamento de Administração 
Isabella Barreira de Sá Pacheco

\title{
ANÁLISE DO COMPORTAMENTO DA GERAÇÃO Y DO RIO DE JANEIRO E NITERÓI NAS DECISÕES DE COMPRA EM SITES DE MODA
}

\author{
Trabalho de Conclusão de Curso
}

[Trabalho de Conclusão de Curso, apresentado ao programa de graduação em Administração da PUC-Rio como requisito parcial para a obtenção do titulo de graduação em Administração.]

Orientadora: Vivian Steinhäuser

Rio de Janeiro

Novembro de 2018. 


\section{Agradecimentos}

Gostaria de agradecer imensamente aos meus pais, Anna Paula e Marcelo, por me proporcionarem a oportunidade de cursar o curso de Administração na PUC - Rio e por toda a sua dedicação, amor e apoio, em qualquer escolha que eu faça. Sou eternamente grata a minha família, principalmente minha irmã Carolina, por toda a sua paciência e maturidade, que me aguentou até nos momentos de maior estresse entre faculdade e trabalho. Agradeço também às minhas avós Jolena e Marisa, e minha dinda Márcia, por estarem sempre comigo, torcendo por mim e sempre me ajudando e aconselhando. Tornei-me quem eu sou hoje em dia graças ao amor e ensinamento deles, e fico muito feliz em ter tido a sorte de ter nascido em uma família tão especial e única. $\mathrm{E}$ um agradecimento cheio de amor para o resto da família toda, que não é pequena.

Aos meus amigos, quero agradecer a cada um que esteve durante essa jornada comigo, tornando o caminho sempre mais leve e feliz. São a família que eu tive sorte de encontrar, e a que eu escolhi como minha. Muito obrigada a todos que estiveram durante todo esse tempo, fazendo com que todos os desesperos e momentos difíceis parecessem fáceis. Além dos meus amigos, gostaria de agradecer toda a oportunidade vivida na PUC durante esses quatro anos e meio, a todos os amigos que fiz, todos os professores que conheci e que contribuíram para o meu conhecimento, que vai muito além do acadêmico.

Gostaria também de agradecer de forma muito especial à minha orientadora, Vivian. Muito obrigada por toda a sua calma e tranquilidade ao longo do processo, deixando mais leve e tranquilo. 


\section{Resumo}

Pacheco, Isabella Barreira de Sá. E-commerce de moda - Análise do comportamento da Geração $Y$ do Rio de Janeiro e Niterói nas decisões de compra em sites de moda. Rio de Janeiro, 2018. Número de páginas: 50. Trabalho de Conclusão de Curso - Departamento de Administração. Pontifícia Universidade Católica do Rio de Janeiro.

O e-commerce vem se expandindo na última década de forma marcante no Brasil e apresenta-se como importante ferramenta de impulsionamento de vendas no mercado da moda. Este estudo teve o objetivo de compreender as particularidades do comportamento de compra dos consumidores da Geração $Y$ do Rio de Janeiro e Niterói em sites de moda no Brasil. Para tal, foi elaborado questionário e disponibilizado pelo WhatsApp para consumidores residentes nestas cidades. Foram analisados 103 questionários.

Palavras- chave: E-commerce, Experiência do usuário, Comportamento do Consumidor 


\section{Abstract}

Pacheco, Isabella Barreira de Sá. Fashion E-commerce - Analysis of the behavior of the Generation $Y$ of Rio de Janeiro and Niterói in the purchase decisions in fashion sites

Rio de Janeiro, 2018. Number of pages: 50. Undergraduate Thesis Departamento de Administração. Pontifícia Universidade Católica do Rio de Janeiro.

E-commerce has been expanding in the last decade in a remarkable way in Brazil and presents itself as an important tool for boosting sales in the fashion market. This study aimed to understand the particularities of the buying behavior of Generation $Y$ consumers from Rio de Janeiro and Niterói on fashion sites in Brazil. For that, a questionnaire was prepared and made available by WhatsApp to consumers residing in these cities. A total of 103 questionnaires were analyzed.

Keywords: E-commerce, User experience, Consumer behavior 


\section{Lista de Figuras}

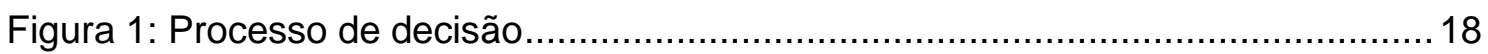

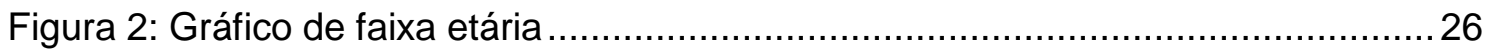

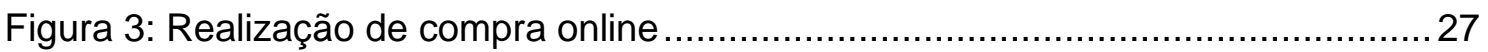

Figura 4: Porque nunca realizou uma compra de vestuário online? ..........................28

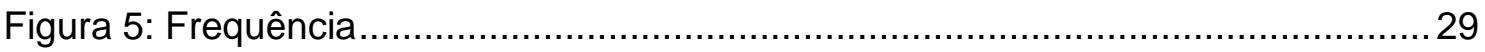

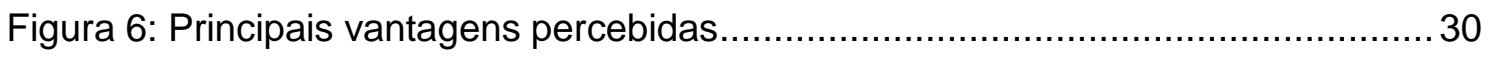

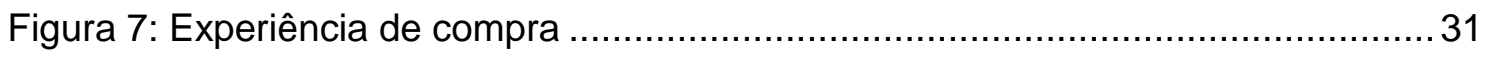

Figura 8: Em uma escala de 1 a 5, sendo 1 pouco e 5 muito, ao escolher um ecommerce de moda para realizar a sua compra, o que mais te chama atenção ..........32

Figura 9: Em uma escala de 1 a 5, sendo 1 pouco e 5 muito, o que você acha

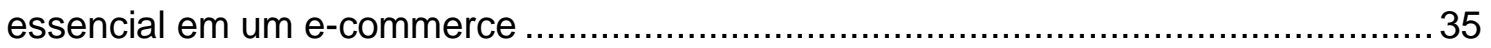

Figura 10: Desvantagens percebidas pelos clientes ............................................... 36

\section{Sumário}




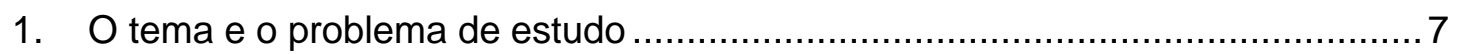

1.1 Introdução ao tema e ao problema do estudo ............................................. 8

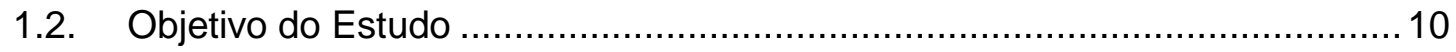

1.3. Objetivos Intermediários do Estudo ….................................................... 10

1.4. Delimitação e foco do estudo ............................................................... 11

1.5. Justificativa e relevância do estudo ........................................................ 11

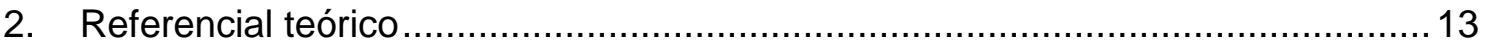

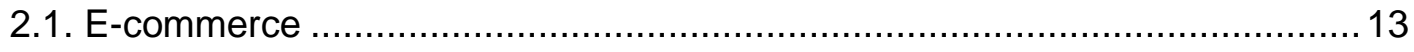

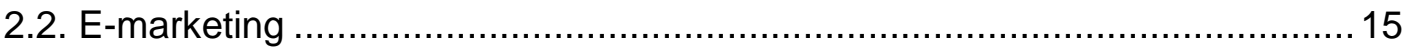

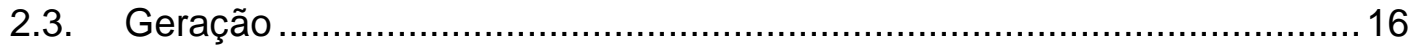

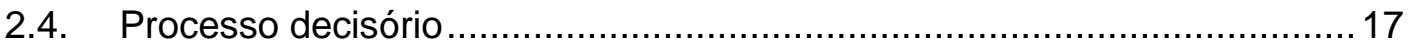

3. Métodos e procedimentos de coleta e de análise de dados do estudo .................21

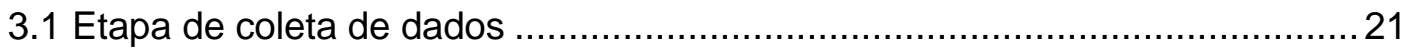

3.2 Fontes de informação selecionadas para coleta de dados no estudo .............22

3.3 Procedimentos e instrumentos de coleta de dados utilizados no estudo .........23

3.4. Limitações do método .................................................................... 23

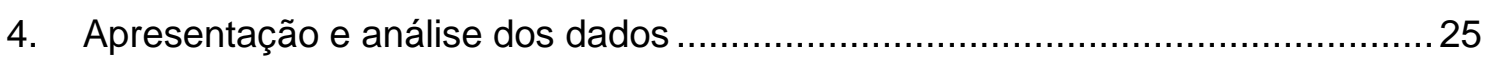

4.1 Perfil da população entrevistada ......................................................... 25

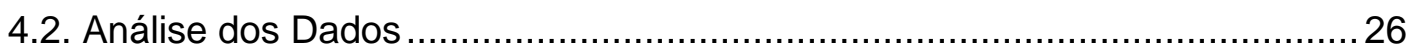

4.3. Descrição e análise dos resultados..................................................... 28

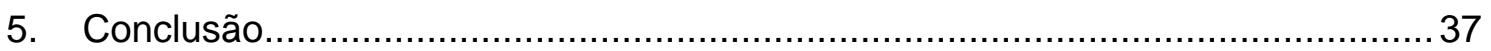

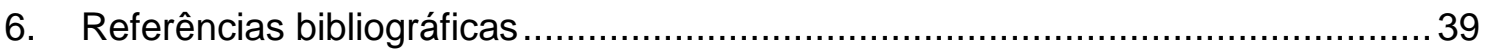

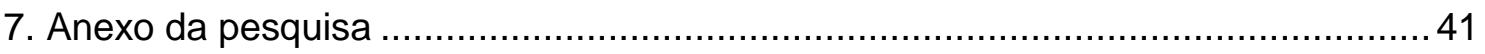

\section{O tema e o problema de estudo}




\subsection{Introdução ao tema e ao problema do estudo}

O comércio eletrônico teve início no Brasil em 1995, mas por um bom tempo revelou participação pouco expressiva no país, quando comparado a outros países, como EUA. Hoje, segundo o EBIT (2017), o Brasil está entre os dez países com maior faturamento em e-commerce do mundo. Em 2017 mais de 55 milhões de consumidores fizeram pelo menos uma compra virtual, demonstrando alta de $15 \%$ em relação ao ano anterior.

Diante dos setores com participação mais significativa no comércio eletrônico brasileiro, o setor de moda tem sido um dos líderes no ranking, tanto em faturamento, como no número de pedidos realizados. O comércio online de vestuário e acessórios vem conquistando um público cada vez maior, sendo mais expressivo no gênero feminino $(66 \%)$ do que no masculino (33\%). Já quando avaliada faixa etária, aquela entre 25-34 anos é a mais participativa, com um ticket médio de $\mathrm{R} \$ 248,20$ de acordo com o Atlas (2017). Além disso, a região Sudeste liderou o ranking de pedidos realizados no ano de 2017, com $67,9 \%$.

Segundo Kotler (2000), o termo e-commerce significa uma ampla variedade de transações eletrônicas, podendo ser de empresa para consumidor (B2C), ou transação de empresa para empresa (B2B). As primeiras transações no mundo tiveram início nos anos 90, e como todo início de um novo conceito, as dimensões e estrutura eram bem pequenas. Mas com a mudança no perfil do mercado mundial, não demorou muito para que este novo conceito de compra e venda se tornasse a maior e mais volumosa maneira de comercializar diversos produtos ou serviços.

"As empresas constroem suas vantagens competitivas através de aplicação das cadeias de valores de forma estrategicamente importantes de uma forma mais barata ou melhor do que a concorrência." (PORTER, 1989). 
Com a evolução da tecnologia e o refinamento das funcionalidades, as empresas perceberam no e-commerce uma maneira de obter uma grande vantagem competitiva, visto que os custos são menores quando comparados com o varejo tradicional e o alcance é maior. É possível que pessoas do mundo inteiro consigam visitar sua loja virtual, por isso, a adesão do mercado tem sido cada vez maior.

De acordo com Kotler (2000), alguns conceitos elementares no varejo nunca vão mudar, sendo três os principais: (1) foco no consumidor e suas necessidades; (2) criar, comunicar e entregar valor sabendo, quais são os valores, necessidades, percepções e crenças dos clientes e (3) lembrar que o objetivo final é ter um consumidor satisfeito e encantado. Assim, é necessário usar de suas métricas e análises disponibilizadas pelas plataformas online para entender como conquistar seu cliente diante dos conceitos expostos acima e alcançar tais conceitos elementares.

Mesmo com diversos avanços, muitas das atitudes são influenciadas pelos costumes e hábitos das gerações, como por exemplo, a Geração Y, que teve seus consumos criados e influenciados pela internet, possuindo mais facilidade e naturalidade ao realizarem compras online.

O conceito da Geração $Y$ abrange aos indivíduos nascidos no inicio dos anos de 1980 até meados de 1990. Essa geração é representada pelos filhos da Geração X (nascidos entre 1965 a 1979) e netos da Geração Baby-Boomers (nascidos 1946 a 1964) e sendo sucedidos pela Geração Z (nascido na metade da década de 90 até os dias de hoje). (OLIVEIRA, 2008).

A geração $Y$ também é denominada de Geração Millenials ou Geração Internet, pois cresceram e se desenvolveram no período dos avanços tecnológicos e prosperidade econômica. Portanto, tendo contato com videogames, computadores, celulares, downloads de músicas e mensagens instantâneas pela internet. Esses fatores os diferem das demais gerações, principalmente por serem os primeiros a sofrer influência da internet no seu 
comportamento, padrão e estrutura de gastos, ato da compra e visão de mundo em relação ao trabalho, políticas.

Seu perfil de consumo é diferente das demais gerações, com facilidade de conhecimento e de se adaptar ao novo. Seus valores consistem em velocidade, liberdade e consumo. Sendo liberais para o consumo e novidades, buscam o prazer no momento de consumir, sempre atentos às mudanças e às inovações.

A presença da Geração $Y$ no comércio online já é muito expressiva, segundo a pesquisa realizada pelo Atlas (2017), a faixa etária entre de 25 a 34 anos representa a maior parcela de consumidores em e-commerce no Brasil. Além disso, a faixa 18-24 é a predominante em Games e Moda e Acessórios.

$O$ presente estudo tem como objetivo analisar o comportamento de compra no setor de moda de consumidores da Geração $Y$ residentes no Rio de Janeiro e Nlterói, sobre a motivação de compra online e sugestões de melhoraria dos serviços dos sites, a fim de cativar a parcela da população que não possui o costume de realizar suas compras pela internet.

\subsection{Objetivo do Estudo}

O objetivo deste estudo foi analisar o comportamento da Geração Y que reside nas cidades do Rio de Janeiro e Niterói acerca de suas decisões de compra em sites de moda.

\subsection{Objetivos Intermediários do Estudo}

Para atingir o objetivo final proposto foram alcançados os seguintes objetivos intermediários: 
- Identificar os sites de e-commerce que têm como principal público

a Geração Y, estudando suas estratégias e particularidades;

- Identificar os atributos mais valorizados pela Geração em questão.

- $\quad$ Analisar o comportamento de compra da Geração Y em sites de moda.

Neste caso, pretende-se realizar a avaliação geral do consumidor a respeito de um produto no varejo online de moda e em quais situações esse comprador realiza suas aquisições, ou seja, como se dá o processo de compra.

\subsection{Delimitação e foco do estudo}

Foram estabelecidos os seguintes critérios de inclusão:

- As pessoas que responderam o questionário deviam apresentar idade entre 18 e 38 anos - Geração Y;

- $\quad$ Serem residentes da cidade do Rio de Janeiro ou Niterói, ambos no estado do Rio de Janeiro;

- A pesquisa foi realizada dentro de dois meses.

\subsection{Justificativa e relevância do estudo}

Apesar da crise financeira que o Brasil vem ultrapassando, o ecommerce tem apresentado crescimento muito expressivo, com aumento de 15\% no ano de 2017 (EBIT, 2017). Surge também como ferramenta de 
propulsão de vendas, sem necessidade de grande investimento. No entanto, são poucos os trabalhos que analisam esta metodologia e mercado potencial.

Muito se sabe na Academia sobre o varejo físico diante de estudos por ser um canal mais tradicional, no entanto, o funcionamento das plataformas e comportamento dos consumidores vem se mostrando bem diferentes em relação ao online, que em contrapartida vem tendo um crescimento expressivo, se tornando ainda mais essencial entender mais a fundo sobre as necessidades de seu cliente e como atende-las.

Além da academia, as informações que esse estudo pretende produzir podem se mostrar de interesse para empresas e instituições que atuam no ramo de moda e possuem ou tem interesse no comercio eletrônico, entendendo mais sobre as necessidades e preferências de seus clientes ou potencias consumidores, entendendo seu processo de compra. Isso se dá pelo fato de que o trabalho pode ajudar essas empresas/ consultorias de ecommerce a compreenderem melhor as preferencias e hábitos desse público quando navegam a procura de produtos, e o que leva os mesmos a finalizarem a compra, tanto em relação às funcionalidades que o site disponibiliza até mesmo como expõe seus produtos na "vitrine" da loja online, estabelecendo estratégias diferenciadas para o público em questão.

Os resultados a serem alcançados também poderão ser úteis para outras pesquisas e trabalhos do meio acadêmico, posto que possam vir a permitir uma reflexão sobre os comportamentos da Geração $Y$ e seus comportamentos no comercio eletrônico. 


\section{Referencial teórico}

A seguir, são apresentados conceitos, visões e abordagens de autores quanto aos temas: e-commerce, marketing digital e moda.

\subsection{E-commerce}

Segundo Fagundes (2009):

"O comércio eletrônico através da internet é o ramo de atividade econômica que mais cresce no mundo. O termo e-commerce deriva do termo comércio eletrônico, onde as negociações são realizadas exclusivamente pelo formato eletrônico, ou seja, pela internet."

Para Fagundes (2009), o e-commerce é utilizado para facilitar ou comercializar produtos ou serviços online, de forma rápida e de fácil acesso para os elementos da sociedade em qualquer parte do mundo, uma vez que se trata de uma forma de comércio à distância, permitindo que o cliente tenha comodidade e praticidade ao realizar uma compra.

Com o surgimento da internet e das inovações tecnológicas, o ecommerce abre um leque de oportunidades de comercializar e fazer negócios. Hoje, é possível realizar uma compra de uma loja online do outro lado do mundo, o que cria uma maior competição, e ao mesmo tempo uma vantagem.

"Por meio do comércio eletrônico, os clientes podem projetar, solicitar produtos e serviços e pagar por eles sem precisar sair de casa. E graças às maravilhas dos serviços de entrega, ainda 
podem receber suas compras em menos de 24 horas. (KOTLER, 2006) “

Atuar no e-commerce é uma grande oportunidade de ingressar nesse mercado mundial em crescente desenvolvimento. Por esse motivo, é cada vez mais frequente empresas investirem no e-marketing e vendas pela internet. No e-commerce, toda relação da empresa com o consumidor final é feita quase sem intermediários, possibilitando assim que os produtos tenham custos menores o que representa maior valor agregado ao serviço.

De acordo com pesquisas no EBIT, o faturamento do e-commerce em 2018 deverá ser de $\mathrm{R} \$ 53,4$ bilhões em 2018, alta de $12 \%$ ante 2017, $\mathrm{O}$ mercado de e-commerce movimentou $R \$ 112,2$ bilhões em 2017 , alta de $20 \%$ ante 2016. Além disso, 27,4 milhões de consumidores fizeram compras no ecommerce, desse total, 4,5 milhões compraram pela primeira vez. Uma das razões apresentadas através da pesquisa feita pelo EBIT, o número de consumidores online está crescendo cada dia mais em razão da facilidade e versatilidade apresentada pelo modo de consumo na Web.

Segundo Esteves (2011) para que se efetuem compras on-line, alguns fatores oferecem fortes contribuições. Um dos mais representativos é definido pela falta de tempo disponível para realização das diversas atividades do cotidiano. Conforme as horas trabalhadas pelos membros da família aumentam, diminui proporcionalmente a quantidade de tempo disponível para pesquisas e compras de produtos da maneira tradicional. Além disto, muito mais do que somente um ponto de venda virtual o e-commerce se tornou uma ferramenta durante todo o ciclo de venda, desde a criação de uma demanda específica até a retenção do cliente na pós-compra.

Para os compradores, o principal benefício é a compra eficiente, ou seja, as lojas on-line proporcionam maior gama de produtos, preços menores e alto nível de serviço personalizado. Sempre inovando na maneira de adquirir novos tipos de produtos e serviços (CASTRO, 2011). 


\subsection{E-marketing}

Segundo Limeira (2007, p. 10):

E-marketing é um conjunto de ações de marketing intermediadas por canais eletrônicos como a internet, em que o cliente controla a quantidade e o tipo da informação recebida.

Analisando a definição de e-marketing é possível constatar que com a chegada do comercio eletrônico, o marketing tradicional teve que se adequar e se diferenciar, permitindo que as empresas se segmentem e estabeleçam suas estratégias a grupos de consumidores dirigidos, customizando assim suas promoções de forma a atender as necessidades e desejos de acordo com o perfil de seus consumidores.

Com a evolução tecnológica da informação e da comunicação, o marketing interativo passou a ser tratado como o marketing digital ou marketing eletrônico, adequando a rapidez que o cliente necessita.

Marketing Eletrônico é o conjunto de ações de marketing intermediadas por canais eletrônicos, como a internet, em que o cliente controla a quantidade e o tipo da informação recebida. (LIMEIRA, 2007)

O marketing eletrônico é estratégia competitiva que tem sido muito adotada pelas empresas. O Marketing Digital tem como premissas as mesmas do Marketing Tradicional, de agregar valor às marcas e produtos, atribuindo maior valor aos consumidores. Apenas o modo como essas premissas são planejadas e executadas são diferentes. O E-marketing tem como característica ser totalmente focado no online, levando tráfego e realizando conversões através de mídias, e tendo resultados que podem ser mensurados de maneira mais assertiva e rápida, sendo a partir de redes sociais, e-mail marketing, entre outros. 
Segundo Saleh e Shukairy (2011), com a mudança do canal principal de venda, hoje, existem novas formas de atingir compradores potenciais. A partir da internet, os clientes teoricamente estão apenas a um clique de distância, no entanto, o desafio se tona maior devido ao grande número de concorrentes, e as informações geradas por eles. Clientes potenciais são bombardeados por mais de 3 mil mensagens publicitárias diariamente.

A competição por atenção é intensa, e os próprios clientes, já conseguem filtrar muito melhorar tantas informações. Assim, é necessário se conectar com os clientes de formas novas, capturar seu interesse, oferecerIhes controle sobre o relacionamento que têm com você e gentilmente os guiar até uma conversão diante do e-commerce. As pessoas recebem diversas mensagens publicitárias e promocionais que buscam persuadi-las a uma ação. Ainda que mídias offline tradicionais possam transmitir essas mensagens, é difícil que as pessoas ajam imediatamente sob o efeito delas. Já na web, um cliente potencial pode receber uma mensagem e, em questão de minutos, clicar em um link para comprar um produto.

\subsection{Geração $Y$}

Segundo Oliveira (2008), o conceito da Geração Y abrange aos indivíduos nascidos no inicio dos anos de 1980 até meados de 1990. Nascidos em meio a tecnologia, essa geração sofreu uma grande mudança na forma com que as pessoas se comunicam, e como até mesmo consomem. A Geração Y já nasceu sendo introduzida a computadores e celulares.

A vida cotidiana dessa geração envolve o uso da tecnologia como forma predominante de interação, com isso, outras características acompanham atitudes, como dinamismo, inquietude e impaciência, videogame, música, 
internet, televisão, criando diferentes visões do mundo e formas de tomadas de decisão.

Para Portes (2008):

"A Geração y é composta por líderes peculiarmente inovadores e quase irrequietos. Embora em sua grande maioria sejam largamente talentosos, sinceros e criativos, demonstram possuir este lado impaciente que ora lhes serve de âncora, ora de empecilho. Isto pelo fato de que não raro estes jovens estão sujeitos a decisões precipitadas com vistas a objetivos maiores, o que os leva algumas vezes a darem "passos maiores que as pernas". Estas atitudes são típicas de jovens que estavam acostumados a um determinado estilo de vida - enquanto em sua graduação onde apenas vislumbravam de longe como em um espelho as atividades reais nos postos de trabalhos que então, rapidamente, passaram a assumir.“

De acordo com Cyrillo (2003) no final da década de 90, uma geração de consumidores atingiu seu ápice, a denominada Geração $\mathrm{Y}$, apresentando um perfil intrigante, gostam de ser estimulados e tem necessidades crescentes de consumo. A Geração $Y$ é filha da tecnologia, por representar a primeira geração da história totalmente imersa na interatividade, hiperestimulação e ambiente digital. Assim, já nasceram habituados com os avanços rápidos, e mudanças não os assustam.

\subsection{Processo decisório}

Segundo Kotler (2006), em geral os consumidores querem ter a possibilidade de comprar bens e serviços de diversas formas, para acomodar 
as mudanças. Assim, o comportamento do consumidor no processo de decisão de compra passa por cinco estágios que podem interferir numa tomada de decisão. As cinco etapas englobam: (1) reconhecimento do problema, (2) busca de informações, (3) avaliação de alternativas, (4) decisão de compra e (5) comportamento pós-compra.

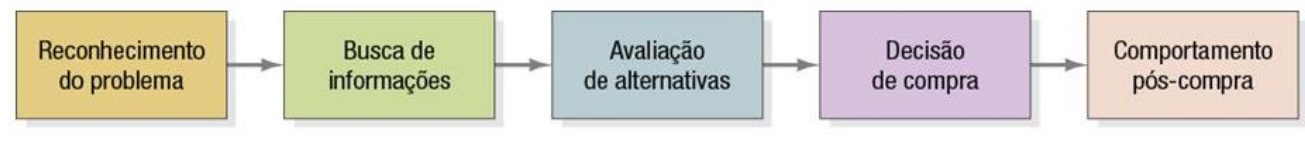

Figura 1: Processo de decisão. KOTLER, P; KELLER, K. Administração de marketing. 12 ed. São Paulo: Pearson Prantice Hall, 2006.

O comportamento do consumidor é um conjunto de referencias que servem de suporte para o conhecimento das culturas, valores, crenças e desejos. Para entender como os consumidores tomam suas decisões de compra, as empresas devem identificar quem são os participantes do processo e quem os influencia (KOTLER, 2000).

Segundo Kotler (2000), o ponto inicial para conhecer e satisfazer as necessidades dos clientes é tentar entender o comportamento do consumidor e estudar como as pessoas, grupos e organizações selecionam, compram, usam e descartam serviço.

De acordo com Peppers e Rogers (2003):

"vive-se atualmente uma descontinuidade tecnológica de proporções épicas, e a maioria de nós não está nem remotamente preparada para tal. $O$ velho paradigma, um sistema de produção em massa, a mídia de massa e o marketing 
de massa estão sendo substituídos por um paradigma totalmente novo, um sistema econômico um-a-um (1:1). O futuro do 1:1 será caracterizado por produção personalizada, mídia de endereçamento pessoal e marketing 1:1, mudando totalmente as regras da concorrência nos negócios e o crescimento. Em vez de fatias de mercado, a meta da maioria da concorrência será a fatia do cliente - um cliente por vez. O futuro 1:1 dos negócios enfocará menos os lucros de curto prazo derivado de volumes de transações trimestrais ou anuais e mais o tipo de lucro que pode ser realizado pela retenção de clientes de longo prazo e de valores vitalícios".

Assim, é importante frisar que o cliente sempre deve estar em primeiro lugar, desde o início do processo de consumo até o pós-compra. É preciso dar um atendimento personalizado, e criar mídias e conteúdos que sejam específicos para cada cliente, afinal, cada um possui comportamentos e atitudes individuais, sejam elas partindo do processo decisório de compra, tamanho, preferência de produto, ou até mesmo cor.

\subsection{Experiência do usuário}

O termo "experiência do usuário" é utilizado quando se refere de experiências online. A empresa Nielsen Norman Group, especializada em consultoria e pesquisas na área de usabilidade e experiência do usuário, define o termo como:

"A experiência do usuário abrange todos os aspectos da interação do usuário final com a empresa, seus serviços e produtos. Os primeiro requisito para uma experiência exemplar é atender às necessidades do cliente, sem complicações. A seguir 
vem a simplicidade e elegância que geram produtos dos quais se tem alegria de possuir e usar. Para atingir uma experiência de alta qualidade em uma empresa deve haver uma fusão entre múltiplas disciplinas, incluindo engenharia, marketing, design gráfico e industrial nas interfaces. "( Nielsen Norman Group, 2011).

Uma boa experiência é algo que só é possível se atingir a partir da integração das áreas criativas e de execução de uma empresa, deve ser um trabalho com sintonia para fornecer ao cliente uma experiência memorável. Por exemplo, por mais que a experiência do cliente seja boa durante a usabilidade do site, ou ao longo de sua compra online, a pessoa ficará insatisfeita caso o produto chegue atrasado, ou mesmo com algum tipo de defeito. A Experiência do usuário precisa fazer parte de todos os processos de venda de um produto, com muita qualidade e atenção, colocando o cliente no centro. Ao longo desse processo, ações podem definir se seu cliente voltará a realizar alguma compra com você, se ele te indicará a amigos, etc. 


\section{Métodos e procedimentos de coleta e de análise de dados do estudo}

\subsection{Etapa de coleta de dados}

Segundo Kauark, Machães e Medeiros (2010) é muito importante conhecer os tipos de pesquisas para definição dos instrumentos e procedimentos que o pesquisador irá utilizar no planejamento de sua investigação. Isto por que o tipo da pesquisa a categoriza na sua forma metodológica de estratégias investigativas. A presente pesquisa tem como objetivo analisar o comportamento de compra da Geração $Y$ que reside no Rio de Janeiro em compras em site de moda. Dessa forma, essa pesquisa pode ser classificada de natureza quantitativa, e seu objetivo é descritivo e explicativo.

De acordo com Kotler (2006), a pesquisa quantitativa é um levantamento de dados a fim de obter de forma numérica o comportamento de pessoas de uma população, como também a frequência desse comportamento e a preferência. Essa pesquisa é efetuada através de questionários, que consiste em um conjunto de perguntas feitas para obter resposta dos entrevistados, traduzindo os resultados em números e informações para possível análise e classificação.

O método de pesquisa foi aplicado virtualmente, através de um questionário no Qualtrics. É importante ressaltar que a distribuição se deu através de grupos, especialmente WhatsApp, Instagram e Facebook, redes sociais onde a presença de pessoas entre 18 e 38 anos mais se encontram. A pesquisa realizada teve uma única fase, com a duração de um mês. A etapa 
seguinte consistiu da análise das respostas via a mesma plataforma de distribuição, o Qualtrics.

Antes de iniciar a divulgação do questionário, foi feito uma pesquisa piloto para verificar possíveis falhas, com o objetivo de disponibilizar perguntas claras e com fácil entendimento, realizando melhorias após esse processo. Essa fase piloto foi aplicada para 10 pessoas que possuem o perfil do público alvo do questionário.

Por meio da análise dos resultados obtidos com o presente trabalho, será possível estudar e analisar o comportamento de compra do público-alvo em e-commerce de vestuário.

A pesquisa, composta de 22 questões, foi dividida em 2 setores, dados demográficos, da pergunta 1 à pergunta 3, e abordagem ao tema, da pergunta 4 à pergunta 19. A presente pesquisa não teve tempo limite estipulado para as respostas, desde que fosse respondida dentro do período abrangido. As respostas foram compiladas e armazenadas através da plataforma do Qualtrics, demonstrando diante de gráficos as respostas obtidas.

\subsection{Fontes de informação selecionadas para coleta de dados no estudo}

Segundo Kotler (1996), a segmentação de mercado é o ato de dividir em grupos distintos de compradores com diferentes necessidades e respostas. A segmentação de mercado serve para dividir os consumidores em grupos para, então, aplicar as estratégias mais indicadas para cada um. 
O público-alvo da presente pesquisa foram pessoas da Geração $Y$ (nascidas entre 1980 e 2000), moradores da cidade do Rio de Janeiro, que já realizaram alguma compra online em sites de moda.

O questionário foi lançado no mês de setembro de 2018 e coletou 102 respostas.

\subsection{Procedimentos e instrumentos de coleta de dados utilizados no estudo}

A forma de tratamento e análise das informações foi feita por estatísticas descritivas, através de gráficos que o sistema Qualtrics monta de acordo com as respostas obtidas, fazendo uso de cálculos de desvio padrão e média e análise de frequência.

\subsection{Limitações do método}

Por se tratar de um tema atual, houve uma dificuldade na busca de teorias usadas para o comercio online e informações sobre $o$ fatores que 0 abrangem em fontes confiáveis, para o Referencial Teórico.

Sobre as limitações encontradas ao longo do desenvolvimento do questionário, não houve muitas, além do tempo limitado disponível para uma 
obtenção mais diversificada de respostas, além disso, as conclusões não podem ser generalizadas a partir da amostra definida, pois não se trata da população como um todo, dessa forma, estes resultados podem apontar apenas tendências de comportamentos. 


\section{Apresentação e análise dos dados}

O presente tópico tem como objetivo apresentar as respostas obtidas através do questionário realizado pela plataforma de pesquisa Qualtrics, analisando assim, os resultados.

É importante ressaltar que a análise representa uma pesquisa de campo realizada para fins acadêmicos.

\subsection{Perfil da população entrevistada}

A pesquisa foi segmentada por cidade, e para isso, foram realizadas perguntas demográficas como filtros para garantir que apenas pessoas que morassem no Rio de Janeiro ou em Niterói respondessem a todas as perguntas.

Também houve segmentação por idade, com base na escala Likert, sendo pré-requisito que os entrevistados tivessem entre 18 e 38 anos, fazendo parte da Geração Y. 


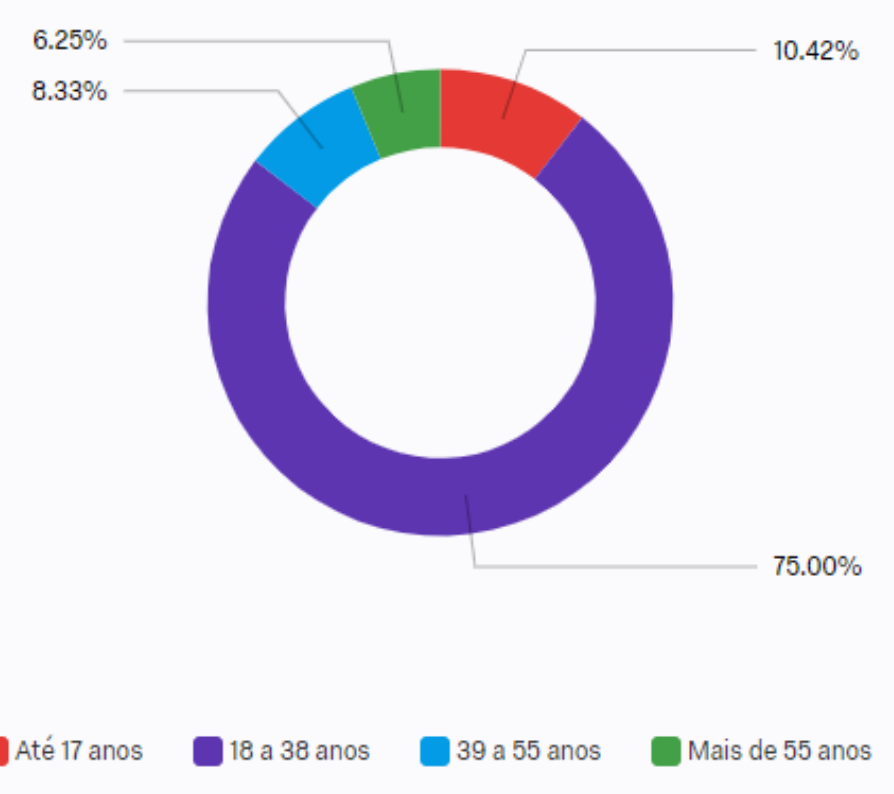

Figura 2: Gráfico de faixa etária

Outra informação coletada na pesquisa referente ao perfil dos respondentes é a definição do sexo. A maioria deles eram mulheres com $80 \%$, e o sexo masculino representou $20 \%$ dos respondentes.

\subsection{Análise dos Dados}

Também foi realizado filtro da população de acordo com a experiência prévia em compras online, que indicou que a maioria dos entrevistados já havia tido esta experiência (92,75\%). Esse dado mostra a representatividade do ecommerce como canal de consumo muito presente hoje no Brasil, assim como citado anteriormente, o país está entre os dez países com maior faturamento em e-commerce segundo o EBIT (2017). E ainda, que apresente um aumento de $15 \%$ aproximadamente por ano.

A representatividade das respostas na pesquisa realizada se torna ainda mais expressiva por ser uma pesquisa segmentada para pessoas que moram em grandes cidades do Sudeste, região que lidera o ranking de números de 
pedidos em 2017 no Brasil, com 67,9\% dos pedidos realizados a nível nacional, de acordo com o Atlas (2017).

No entanto, apesar da população avaliada representar uma dos segmentos mais ativos no e-commerce, é perceptível certa resistência em comprar acessórios ou vestuários online.

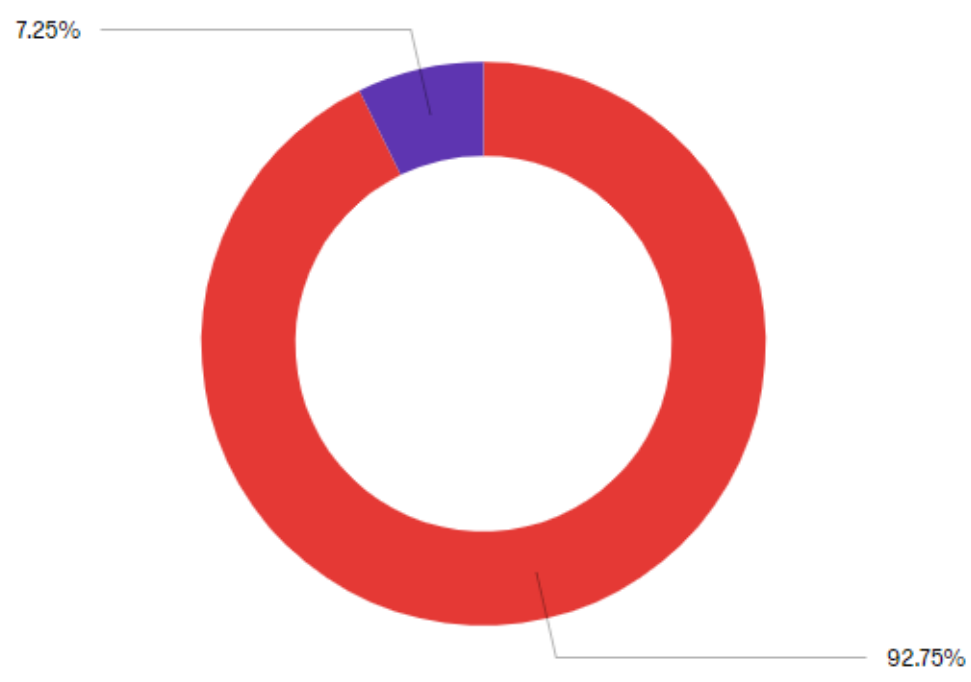

Sim Não

Figura 3: Distribuição da população entrevistada inicialmente, de acordo com a experiência prévia de compras online, como parte dos critérios de inclusão utilizados.

Para entender os principais motivos de nunca terem realizado uma compra de acessório ou vestuário online, $100 \%$ das respostas foram "Falta de costume". Assim, entende-se que, apesar de ser cada vez mais disseminada a cultura de realizar compras no online e não no varejo físico, ainda existe certa resistência por ser uma experiência de consumo diferente do comum. 


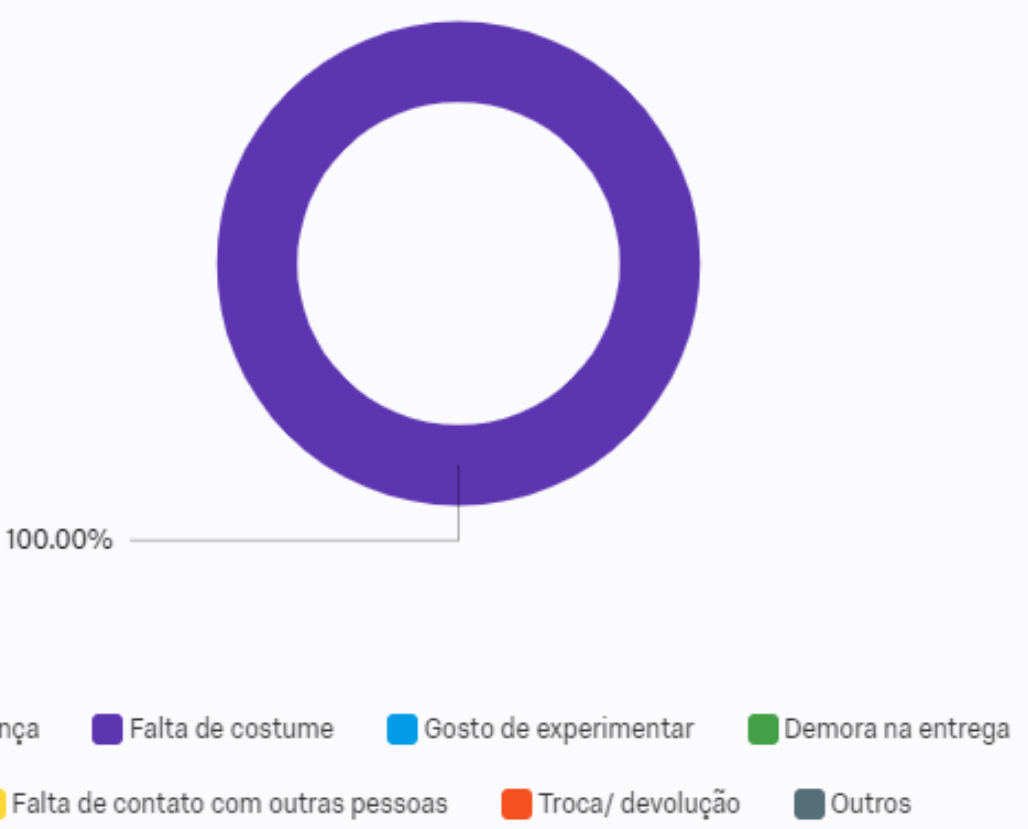

Figura 4: Distribuição dos motivos para não comprar acessórios ou vestuário online de acordo com a população foco do estudo.

\subsection{Descrição e análise dos resultados}

As próximas perguntas tinham o objetivo mapear o comportamento de compra dos consumidores que já realizaram compras online e entender suas percepções.

Após o filtro, as pessoas que responderam que já realizaram alguma compram de vestuário ou acessório online foram questionadas sobre "Com que frequência você realiza compras online?". Diante dos resultados, 48,3\% das pessoas responderam mensalmente, $30 \%$ semestralmente, $15 \%$ anualmente, $1,67 \%$ semanalmente e $5 \%$ quinzenalmente. Dessa forma, percebe-se que aproximadamente a metade desta população compra mensalmente, mas 
quantidade semelhante realiza compras apenas semestralmente ou anualmente, demonstrando o potencial de ampliação de vendas.

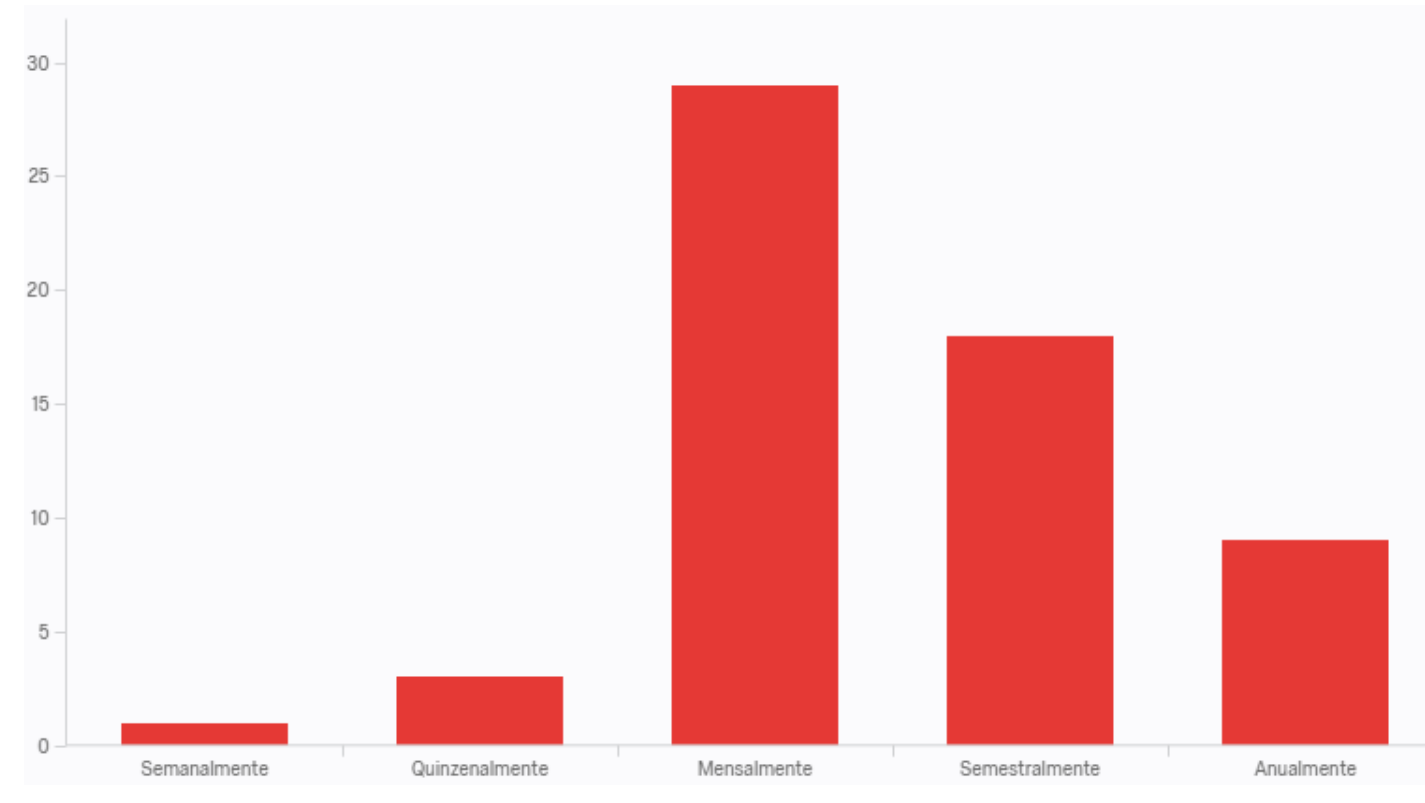

Figura 5: Distribuição da frequência de compra nos sites de acessórios ou vestuário online de acordo com a população foco do estudo.

A pergunta seguinte do questionário tinha como objetivo entender quais são os principais motivos que levam uma pessoa a realizar uma compra em um e-commerce de moda. A maioria dos respondentes $(27,44 \%)$ opta por realizar compras online por conta da Praticidade apresentada, seguido por Comodidade $(23,80 \%)$, Facilidade (15,85\%), Preço (15,85\%), Variedade $(12,80 \%)$. Além disso, Forma de pagamento (3,66\%) e Segurança com (1\%) como mostra a Figura abaixo. 


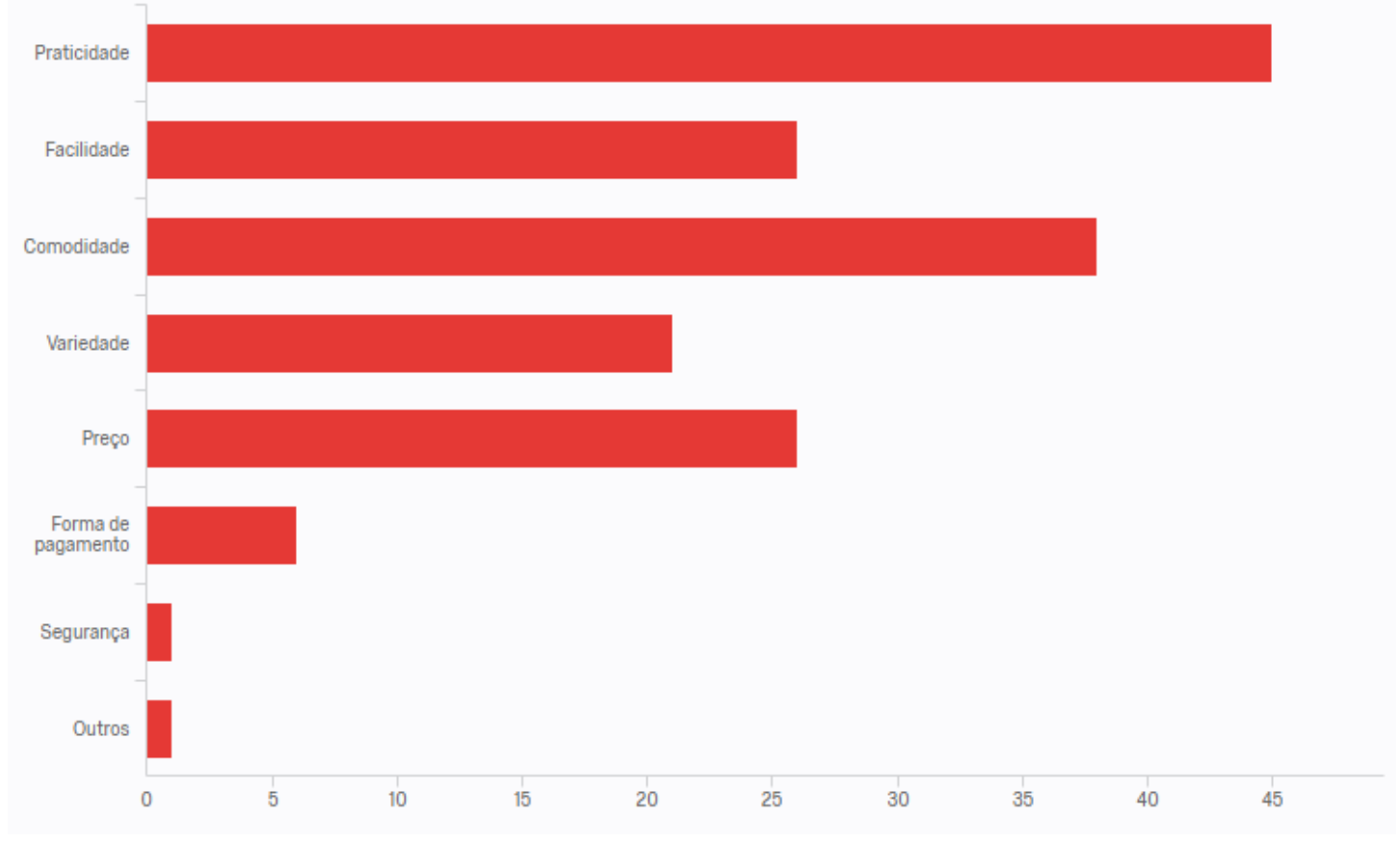

Figura 6: Distribuição dos fatores positivos escolhidos pela população com foco no estudo

Com o intuito de entender a satisfação diante da ultima experiência de compra online dos participantes, foi realizada a pergunta, a qual teve um resultado em sua maioria positivo, com 61,40\% em "Ótimo" e 29,82\% em Bom. Foi pedido para explicar o porquê da resposta (ótimo, bom, regular, ruim, péssimo) da pergunta feita: "Como você avaliaria sua ultima compra de roupa/ acessório online?". A maioria que respondeu "ótimo" ou "bom" alegou que recebeu o pedido realizado dentro do prazo estipulado e que o produto era como descrito no site, além da foto ter sido bem fiel ao produto real.

As pessoas que tiveram como resposta "Ruim" e "Péssimo" em sua maioria alegaram que o contato com o SAC foi difícil, e que tiveram bastante dificuldade em concluir a troca ou devolução do produto, tornando a experiência de compra ruim. Além disso, algumas dessas pessoas que tiveram esse tipo de experiência alegaram que não arriscariam novamente comprando nesses sites. 


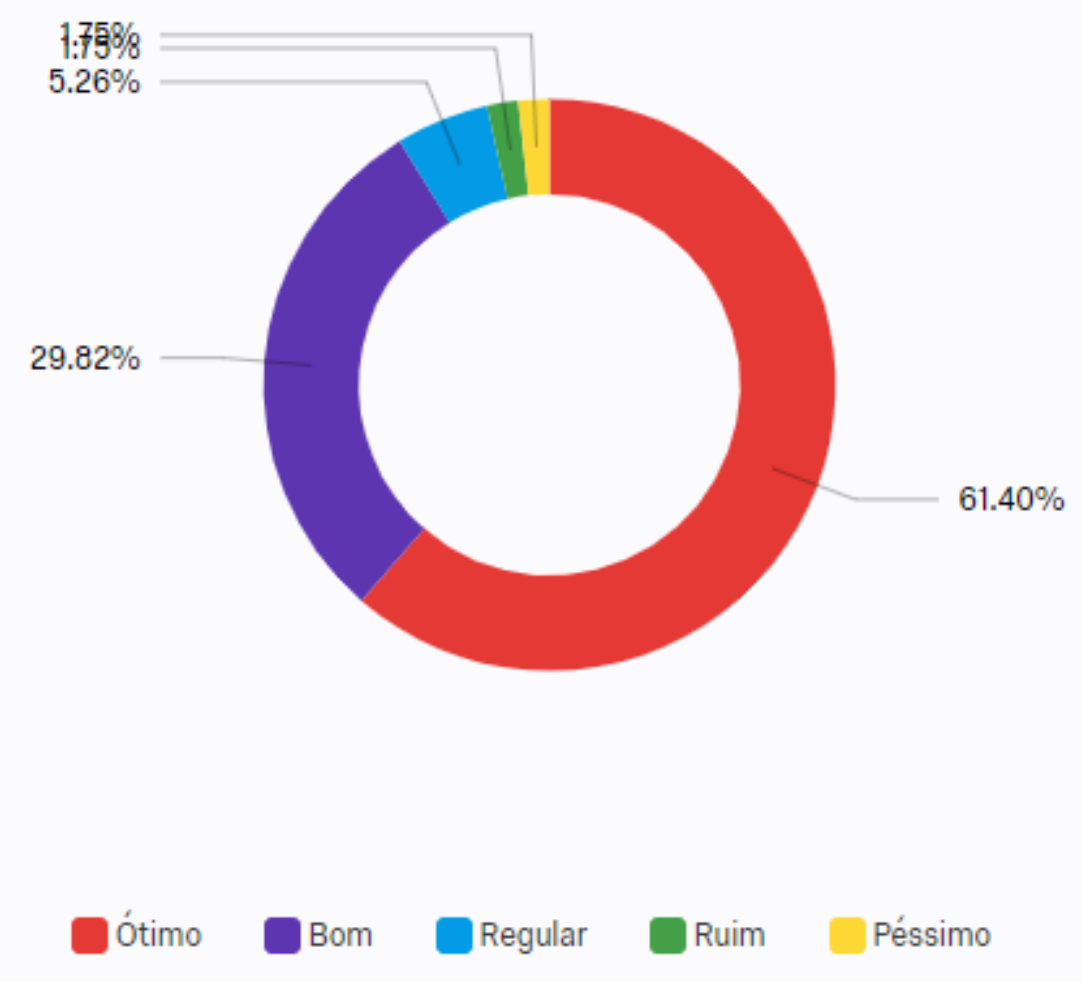

Figura 7: Distribuição opinião sobre última experiência de compra online

Esses resultados chamam atenção para fatores nos quais as empresas devem se atentar para que a experiência de seu cliente seja a melhor possível, e até mesmo para conseguir reter um cliente pós-compra, ultima etapa do processo decisório de compra do consumidor. É importante que as empresas deem uma atenção especial para o contato pós-compra de seu cliente de forma personalizada, visando satisfazer o cliente em suas necessidades de trocas e devoluções. Hoje, grande parte das empresas não possui um SAC totalmente personalizado, ou mesmo que se antecipa ao problema, dando assistência ao seu consumidor antes mesmo de haver reclamação. Assim como citado anteriormente, é necessário que todo o atendimento, mídia e contato com o cliente seja personalizado, assim como mencionado por Pepper e Rogers (2003), é preciso que seja "1:1". A necessidade atual é que os negócios foquem menos nos lucros de curto prazo derivado de volumes de transações e 
mais o tipo de lucro que pode ser realizado pela retenção de clientes de longo prazo e de valores vitalícios.

Assim, é preciso ter uma equipe bem preparada para realizar 0 atendimento caso alguma coisa dê errado, e, além disso, ter um processo eficiente caso o cliente opte por trocar ou devolver o objeto. Caso a experiência nesse estágio seja ruim, esse fator pode definir se o cliente voltaria a comprar ou não em uma marca.

Com o intuito de entender quais são os fatores mais importantes em um e-commerce para os respondentes, foi realizada a pergunta "Em uma escala de 1 a 5 , sendo 1 pouco e 5 muito, ao escolher um e-commerce de moda para realizar a sua compra, o que mais te chama atenção". Os itens abordados foram Preço, Qualidade, Design, Confiabilidade e Indicação. Como demonstrado nos resultados do Gráfico abaixo, preço e qualidade dominam como os fatores de maior importância ao escolher um e-commerce.

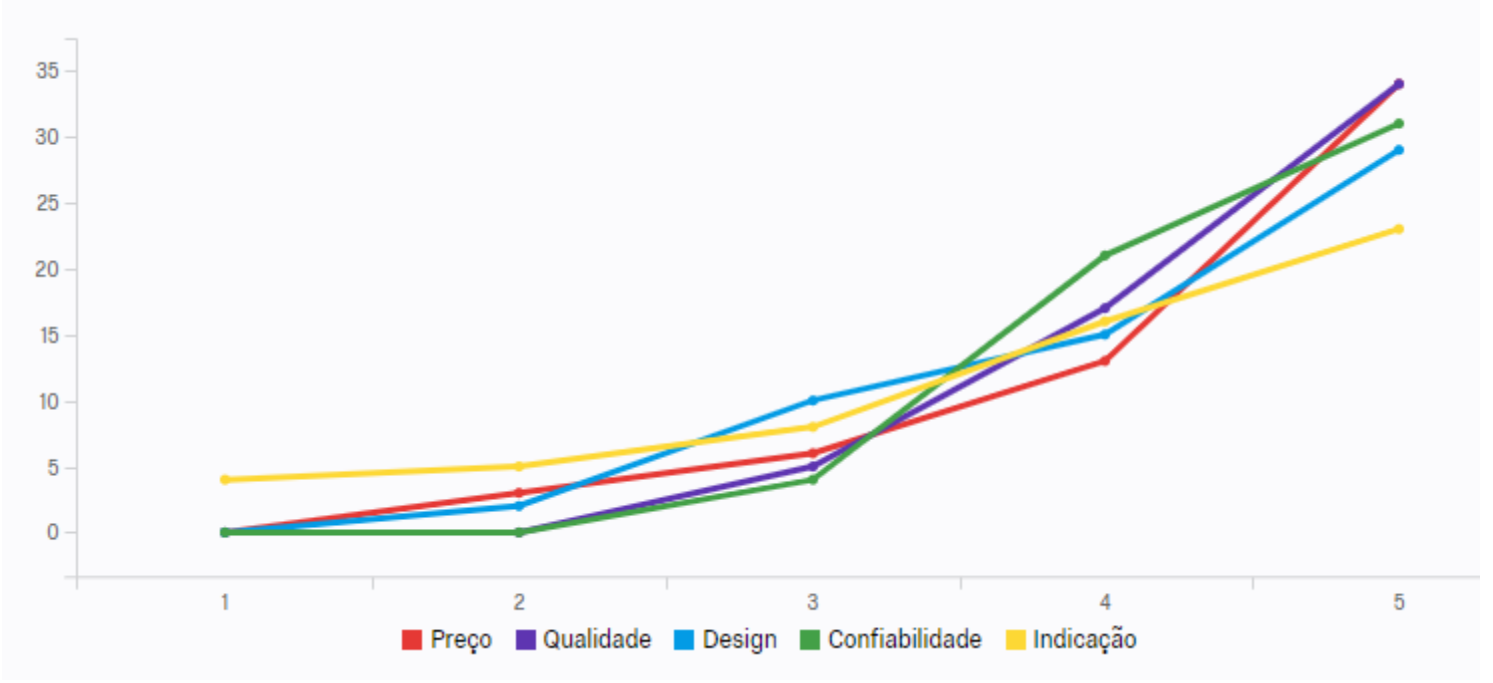

Figura 8: Distribuição da escala dos pontos mais atrativos durante a escolha entre um site ou outro

O fator visto como o que chama mais atenção do cliente durante a sua escolha de compra foi Preço. Assim como citado anteriormente, o ticket médio em compras online no setor de moda não é muito expressivo em comparação a 
outros setores, afirmando a partir disso, que os consumidores são sensíveis ao preço no comercio eletrônico em vestuário e acessórios. Além disso, as barreiras de entrada no mercado online são inexpressivas comparadas ao varejo físico, tornando a competição muito mais acirrada.

Outro fator que reafirma as análises sobre sensibilidade e grande competitividade são mostrados a partir do gráfico abaixo, o qual obteve resultado a partir da questão "Em uma escala de 1 a 5 , sendo 1 pouco e 5 muito, durante compras online você costuma:", pergunta na qual teve como objetivo entender o comportamento de consumo dos respondentes sobre as etapas do processo decisório nos estágios de Busca de informações e Avaliação de alternativas. Durante esses estágios, é possível perceber que os moradores do Rio de Janeiro e Niterói, que fazem parte da Geração Y, têm como costume durante suas compras online, possuir um comportamento mais comedido, tendo como prioridade pesquisar outros sites antes de realizar alguma compra, comparando os fatores mais relevantes como preço e qualidade ao escolher finalizar sua compra em um e-commerce.

Assim, o ideal seria que os sites tenham vantagens competitivas em relação aos fatores mais importantes para seus clientes, sejam eles incentivos em relação aos preços, criação de promoções, ou até mesmo dar enfoque em peças que tenham um ticket médio menor, ou que já estejam com alguma baixa de preço, dessa forma, convertendo de forma mais assertiva. 


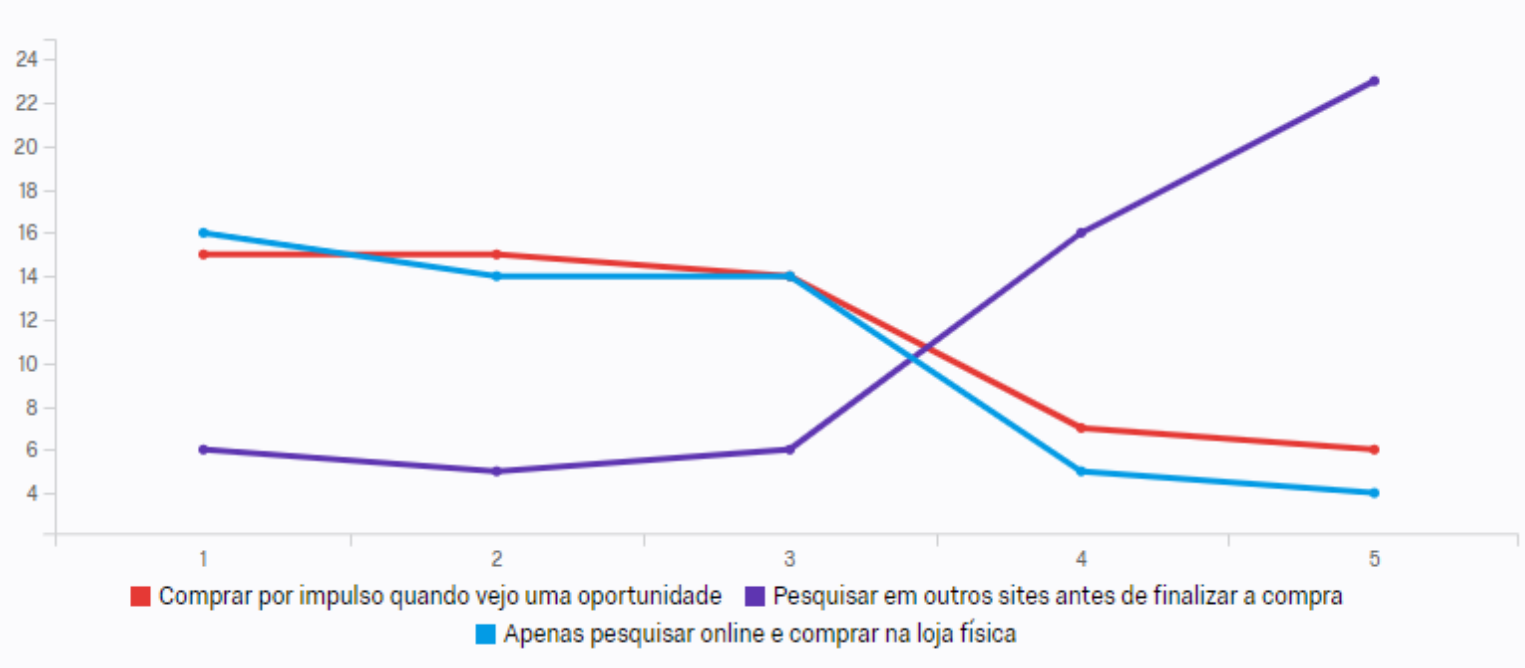

Figura 9: Distribuição de comportamento ao realizar uma compra online

As próximas perguntas têm como objetivo abordar a experiência do cliente nos sites, termo conhecido como Experiência do usuário, assim como citado no referencial teórico. A intenção era mapear seu comportamento e as percepções nesse meio. A primeira pergunta teve como objetivo entender o que os participantes acham essencial em um e-commerce em relação à usabilidade do site, produtos, pagamento e navegação. Os resultados mais expressivos foram "Ter boas fotos" e "Possuir plataforma de pagamento confiável". 


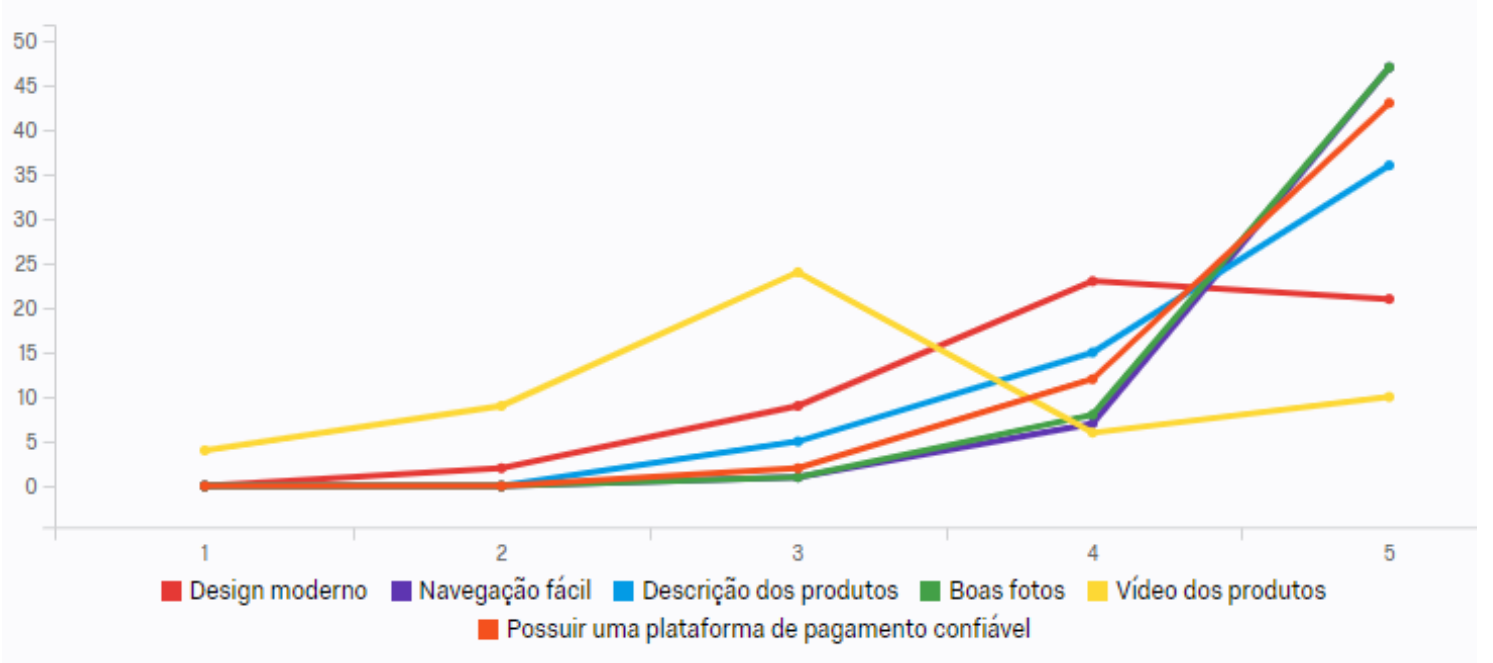

Figura 10: Distribuição de escala sobre pontos mais relevantes à experiência do usuário durante uma compra

A outra pergunta relacionada à experiência do usuário foi uma pergunta aberta, com o intuito de abranger um grande número de insights sobre melhorias que poderiam ser feitas, a partir de fatores que as pessoas mais sentiam falta nos sites de e-commerce de moda brasileiros.

Os assuntos mais abordados foram: ter mais fotos mostrando os detalhes dos produtos; descrições que falem melhor sobre tecido e composição; ter a possibilidade dos clientes relatarem suas opiniões nas páginas dos produtos, sobre como a peça veste, se o tamanho é fiel ao descrito na tabela; devolução e troca mais eficientes; e o assunto mais citado foi a falta de uma tabela de medidas fiel ao tamanho do produto, visto que muitas vez as empresas não tem um padrão de tamanho de produto para produto, e sim uma média.

Diante das respostas, é possível entender que em muitos processos nos sites brasileiros, não existe uma sintonia entre os setores para que haja uma experiência memorável do cliente, assim como abordado na análise de Experiência do usuário. Por exemplo, o ideal seria que existisse durante a produção das roupas ou sapatos um padrão de tamanho fiel ao da tabela de 
medidas, para que o cliente possa comprar de forma mais assertiva, diminuindo até mesmo a quantidade de devoluções e trocas dos produtos.

A próxima pergunta aborda as maiores desvantagens percebida pelos respondentes sobre realizar compras online. Quanto as maiores desvantagens, são percebidas: Não experimentar o produto com 53,93\% e Troca e Devolução com $29,21 \%$. Mostrando mais uma vez que o cliente sente falta de mais informações dos produtos durante uma compra, sendo como Tabela de Medida mais fiel, como citado anteriormente, além de mais fotos com detalhes, descrições, composição, etc. Além disso, assim como percebido, uma das maiores reclamações e fatores que incomodam o cliente é o presente na ultima etapa do Processo Decisório, o pós compra, principalmente o de troca e devolução.

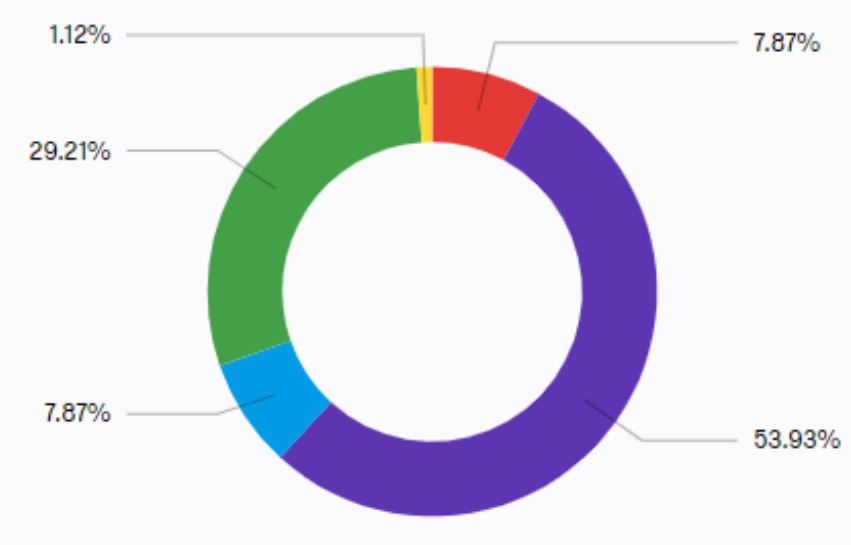

Figura 11: Distribuição dos fatores negativos escolhidos pela população com foco no estudo 


\section{Conclusão}

Ao longo dos anos, o crescimento do comércio eletrônico no Brasil e no mundo tem sido expressivo, segundo o EBIT (2018), a previsão de faturamento para o presente ano, é $12 \%$ maior que o ano anterior. Assim, as empresas e 0 meio acadêmico têm voltado seus holofotes sobre esse canal. Por ser um meio mais recente, ainda não existem muitos estudos acerca do comportamento do consumidor no e-commerce. Dessa forma, este trabalho pretendeu estudar como se da o processo de compra dos moradores do Rio de Janeiro e Niterói em comércios eletrônicos no setor de vestuário e acessórios, para entender o comportamento do consumidor, investigando suas preferências e necessidades.

Para atingir aos objetivos pretendidos realizou-se uma pesquisa quantitativa. Foram coletadas 102 respostas ao longo de um mês, o público foi segmentado em três etapas e foram realizados filtros ao inicio da pesquisa, diante de informações como localização, idade e se o respondente já havia realizado alguma compra online, com o objetivo de obter respostas apenas do perfil delimitado nos objetivos. Os dados foram tratados por meio de um modelo de questionário estruturado, disponibilizado online.

Dentre as principais questões abordadas, conclui-se que a Geração $Y$ residente das cidades do Rio de Janeiro e Niterói mostrou ser adepta à compras online, já que $92,75 \%$ dos entrevistados afirmaram que já haviam utilizado o e-commerce e quase metade deles realizam compras online mensalmente. A praticidade, associada à facilidade e comodidade fizeram parte das principais motivações do grupo estudado em realizar compras online, assim, é perceptível que o processo precisa ser o mais simples possível, tanto em relação à navegação do site, diminuindo o número de clicks e esforço do cliente para chegar ao pagamento de sua compra, quanto no processo de 
entrega à domicílio. E ainda, que o e-commerce apresenta amplo potencial de expansão, já que quase a metade dos entrevistados da Geração Y compra apenas uma ou duas vezes ao ano.

Diante das experiências de compra em e-commerce de moda, foi possível concluir que a grande maioria não está satisfeita com o processo pós-compra. A insatisfação se dá, em sua maioria, pela etapa de troca ou devolução, alegando que o processo é complicado, e que o contato com as empresas é difícil.

Outro fator importante que foi possível concluir é que existe uma sensibilidade na população estudada em relação ao preço. O comportamento do consumidor em relação à etapa de Avaliação de alternativas é caracterizado pela pesquisa em outros sites antes de realizar uma compra, comparando em sua maioria, preço e qualidade, antes que a decisão seja tomada.

Para pesquisas futuras, recomenda-se um estudo que investigue mais a fundo as motivações e o que levaria as pessoas que nunca compraram vestuário ou acessório online a realizar sua primeira transação. Além disso, caberia entender melhor o que faria os consumidores a comprarem de forma mais imediata em um site, quebrando o processo de muita procura antes de finalizar uma compra, como alegado na pesquisa. Entender se existem gatilhos que as empresas podem usar que possam quebrar o processo, como promoções com pequenas durações. 


\section{Referências bibliográficas}

ATLAS (2017) disponível em: http://neomove.com.br/ftpUpload/uploads/Ebook Atlas E-commerce Radar Consolidado2017.pdf Acesso: 3 mai. 2018.

CASTRO, Wellington César de. E-commerce - Vantagens para consumidores e para as empresas. 2011. Disponível em: Acesso em: maio 2018.

CYRILLO, D.C; SAES, M. S. M; BRAGA, M. B. Tendências do consumo de alimentos e o Plano Real: uma avaliação para a grande São Paulo. IPEA. Disponível em: Acesso em: 12 fev. 2003.

E-BIT.

Disponível em

file://C:/Users/isabellapacheco/Downloads/Webshoppers_37\%20(1).pdf Acesso: 3 mai. 2018.

ESTEVES, Yohans de Oliveira. Marketing, Internet e o Comportamento do EConsumidor. In: CONGRESSO NACIONAL DE EXCELÊNCIA EM GESTÃO, 7., 2011, Rio de Janeiro.

GARRETT, Jesse J. The elements of user experience: user-centered design for the Web and beyond. 2nd ed. Berkeley CA: New Riders, 2011.

KOTLER, PHILIP (2000). Administração de Marketing. 10a Edição. São Paulo, Prentice Hall.

Kotler, Philip \& Keller, Kevin Lane (2006). Administração de Marketing. Ed. Pearson Education. 12. ed. São Paulo: Pearson Education.

LIMEIRA, Tania M. Vidigal. E-marketing: o marketing na internet com casos brasileiros. $2^{\underline{a}}$ ed. Ver. E atualizada. São Paulo: Saraiva, 2007. 
OLIVEIRA, D. P. R.. Teoria geral da administração: uma abordagem prática. São Paulo: Atlas, 2008.

PORTER, Michael. Estratégia competitiva: técnicas para análise das indústrias e da concorrência. 7. ed. Rio de Janeiro: Campus, 1991.

PORTES, Gustavo. Geração Y - características e liderança: uma discussão sobre a importância do autoconhecimento no desenvolvimento da confiança e de uma cultura da transparência para estes líderes. Ponta Grossa: UEPG, 2008.

RIBEIRO, K. T. E-commerce - atraindo e conquistando clientes para o varejo virtual. Sinop, Mato Grosso, Brasil. (2007).

SALEH, Khalid; SHUKAIRY, Ayat. Otimização de conversão: a arte e a a ciência de converter prospects em clientes. Sebastopol: O'reilly, 2011. 


\section{Anexo da pesquisa}

Start of Block: Bloquear 2

Comportamento

do

consumidor

em

compras

online

O seguinte questionário tem como objetivo identificar o perfil do consumidor carioca e fluminense que realizam compras pela internet. Os resultados obtidos serão submetidos às análises que farão parte da defesa de monografia. 
Q1 Qual a sua faixa etária

Até 17 anos (1)

18 a 38 anos (2)

39 a 55 anos (3)

Mais de 55 anos (4)

Skip To: End of Survey If Q1 = Até 17 anos

Skip To: End of Survey If Q1 = 39 a 55 anos

Skip To: End of Survey If Q1 = Mais de 55 anos

Q2 Onde você mora

Rio de Janeiro (1)

Niterói (2)

São Gonçalo (3)

Outros (4)

Skip To: End of Survey If Q2 = São Gonçalo

Skip To: End of Survey If Q2 = Outros 
Q3 Qual seu gênero

Feminino (1)

Masculino (2)

End of Block: Bloco de perguntas padrão

Start of Block: Bloco de perguntas padrão

Q5 Você já comprou alguma roupa/ acessório online?

$\operatorname{Sim}(1)$

Não (2) 
Q6 Com que frequência você realiza compras em sites?

Semanalmente (1)

Quinzenalmente (2)

Mensalmente (3)

Semestralmente (4)

Anualmente (5) 
Q8 Quais são os principais motivos que te levam a fazer compras pela internet: (escolha uma opção ou mais)

Praticidade (1)

Facilidade (2)

Comodidade (3)

Variedade (4)

Preço (5)

Forma de pagamento (6)

Segurança (7)

Outros (8) 
Q12 Em uma escala de 1 a 5, sendo 1 pouco e 5 muito, durante compras online você costuma:

$1(1)$

$2(2)$

$3(3)$

$4(4)$

$5(5)$

Comprar por
impulso
quando vejo
uma
oportunidade

(1)

Pesquisar em

outros sites

antes de

finalizar a

compra (2)

Apenas

pesquisar

online $e$

comprar na

loja física (4) 
Q13 Como você avaliaria sua ultima compra de roupa/ acessório online?

Ótimo (1)

Bom (2)

Regular (3)

Ruim (4)

Péssimo (5)

Q20 Explique o motivo da sua resposta na questão anterior: 
Q14 Em uma escala de 1 a 5, sendo 1 pouco e 5 muito, ao escolher um e-commerce de moda para realizar a sua compra, o que mais te chama atenção

\begin{tabular}{|c|c|c|c|c|c|}
\hline & $1(1)$ & $2(2)$ & $3(3)$ & $4(4)$ & $5(5)$ \\
\hline Preço (1) & & & & & \\
\hline Qualidade (2) & & & & & \\
\hline Design (3) & & & & & \\
\hline $\begin{array}{l}\text { Confiabilidade } \\
\text { (4) }\end{array}$ & & & & & \\
\hline Indicação (5) & & & & & \\
\hline
\end{tabular}


Q16 Em uma escala de 1 a 5, sendo 1 pouco e 5 muito, o que você acha essencial em um ecommerce

\begin{tabular}{|c|c|c|c|c|c|}
\hline & $1(1)$ & $2(2)$ & $3(3)$ & $4(4)$ & $5(5)$ \\
\hline $\begin{array}{l}\text { Design } \\
\text { moderno (1) }\end{array}$ & & & & & \\
\hline $\begin{array}{l}\text { Navegação } \\
\text { fácil (2) }\end{array}$ & & & & & \\
\hline $\begin{array}{l}\text { Descrição dos } \\
\text { produtos (3) }\end{array}$ & & & & & \\
\hline Boas fotos (4) & & & & & \\
\hline $\begin{array}{l}\text { Vídeo dos } \\
\text { produtos (5) }\end{array}$ & & & & & \\
\hline $\begin{array}{l}\text { Possuir uma } \\
\text { plataforma de } \\
\text { pagamento } \\
\text { confiável (6) }\end{array}$ & & & & & \\
\hline
\end{tabular}


Q17 O que te influencia mais e fornece informação suficiente quando você deseja pesquisar algum produto novo, que nunca comprou antes?

Opinião de parentes e amigos (1)

Indicação de influenciadores (2)

Comentários nas redes sociais da marca (3)

Pesquisa no Google (4)

Q18 O que você mais sente falta na experiência de consumo em sites de moda brasileiros? 
Q19 Na sua opinião, quais são as maiores desvantagem de comprar online?

Segurança (1)

Não experimentar o produto (2)

\title{
Entrega (3)
}

Troca ou devolução (4)

Falta de contato com pessoas (5)

\author{
Skip To: End of Survey If Q19 = Segurança \\ Skip To: End of Survey If Q19 = Não experimentar o produto \\ Skip To: End of Survey If Q19 = Entrega \\ Skip To: End of Survey If Q19 = Troca ou devolução \\ Skip To: End of Survey If Q19 = Falta de contato com pessoas
}

End of Block: Bloco de perguntas padrão

Start of Block: Bloco de perguntas padrão

Display This Question:

If $Q 5=$ Não 
Q26 Porque nunca realizou uma compra de vestuário online?

Segurança (1)

Falta de costume (2)

Gosto de experimentar (3)

Demora na entrega (4)

Falta de contato com outras pessoas (5)

Troca/ devolução (6)

Outros (7) 
